\title{
Literacy and Engineering Design (Curriculum Exchange)
}

Ms. Mary McCormick, Tufts University

Elissa C Milto, Tufts Center for Engineering Education and Outreach 


\section{Novel Engineering}

Target Grades: K-8

Tufts Center for Engineering Education and Outreach is working to enhance the ability of teachers to effectively cover STEM topics. Inspired by kids and grounded in research, Novel Engineering is an innovative approach to integrate engineering and literacy in elementary and middle school. As part of Novel Engineering students develop projects based on texts they read in English Language Arts or other content classes, such as history. The characters become their clients and students pull information from the text to scope problems and set constraints as they engage in engineering design. The open-ended design context provides students with space to explore their ideas through engineering while working towards classroom goals. Teachers play an integral role in supporting student learning in engineering by providing a supportive, responsive environment that will allow students to build on their ideas as they work on complex, ill-defined problems.

Students use classroom literature-stories, novels, and expository texts- as basis for engineering design challenges to:

- identify engineering problems,

- impose constraints by using details from the text,

- design functional, realistic solutions for characters,

- engage in the Engineering Design Process while reinforcing their literacy skills and

- use evidence from the text to support their design decisions.

\section{Integrating Reading and Engineering}

In an integrated unit, reading the text can support the engineering and doing engineering can help students understand the text. Moving between text and engineering helps support learning in both areas. Students begin by reading a book and discussing problems encountered by the characters. At some point, either during reading or upon completion of the book, the students design something that they can build in the classroom that will solve one of the problems in the book.

\section{The Benefits of Novel Engineering}

Novel Engineering is an engaging way to introduce engineering to a classroom, providing an authentic purpose for the use and practice of language arts. In addition, the subject area of language arts provides an engineering entry point for teachers that is more familiar and a fits into tightly-scheduled lesson plans.

Some of the benefits include:

- It is a highly-adaptable approach that works within an already existing language arts curriculum where teachers choose books that work best in their classrooms.

- It is an exciting and different way to practice literacy and students who struggle with language arts have a new way to demonstrate comprehension.

- It enhances the comprehension of text as students try to find details to predict characters' choices. Students relate to the characters as they work to create solutions for them.

- It introduces students to rich, realistic engineering problems.

- It provides synergistic integration of different disciplines.

- It emphasizes problem-solving, teamwork skills and other $21^{\text {st }}$ Century Skills.

- It meets common core and next generation science standards.

\section{More information and resources for implementation can be found at novelengineering.org.} National Science Foundation 